\title{
Seconds Imputed
}

National Cancer Institute

\section{Source}

National Cancer Institute. Seconds Imputed. NCI Thesaurus. Code C81215.

An imputed time that includes the second of observation. 